\title{
Endothelial dysfunction of internal thoracic artery graft in patients with chronic kidney disease
}

\author{
Takeshi Kinoshita, PhD, MD, ${ }^{\mathrm{a}}$ Masashi Tawa, PhD, ${ }^{\mathrm{b}}$ Tomoaki Suzuki, PhD, MD, ${ }^{\mathrm{a}}$ \\ Yoshinari Aimi, PhD, MD, ${ }^{\mathrm{c}}$ Tohru Asai, $\mathrm{PhD}, \mathrm{MD},{ }^{\mathrm{a}}$ and Tomio Okamura, $\mathrm{PhD}, \mathrm{MD}^{\mathrm{b}}$
}

\begin{abstract}
Objectives: The present study was designed to evaluate the association between chronic kidney disease and the endothelial function of internal thoracic artery (ITA) grafts in patients undergoing coronary bypass surgery. An isometric tension study was performed in ITA strips obtained during surgery. Concentrationresponse curves for acetylcholine (ACh) and sodium nitroprusside were constructed in ITA strips partially precontracted with phenylephrine under the inhibition of cyclooxygenase. The integrity of the endothelium was verified histologically by en-face staining of the luminal surface with the use of silver nitrate solution.
\end{abstract}

Results: In endothelium-intact ITA strips, ACh produced a concentrationdependent relaxation in patients with glomerular filtration rate (GFR, $\mathrm{mL} / \mathrm{min} /$ $\left.1.73 \mathrm{~m}^{2}\right)>60$. A concentration-dependent relaxation response also was observed in patients with GFR 30 to 60 , but it was reduced significantly compared with those with GFR $>60$. In both groups, removal of endothelium or treatment with nitric oxide (NO) synthase inhibitors almost abolished the ACh-induced relaxation. On the other hand, in patients with GFR $<30$, mild contraction rather than relaxation was induced at a high concentration of $\mathrm{ACh}$, which was modified neither by treatment with NO synthase inhibitors nor by removal of the endothelium. Vasodilator responses to sodium nitroprusside were comparable among the 3 groups. The relaxation of endothelium-intact strips to a peak ACh concentration correlated positively with GFR. This relationship held true in a multiple linear regression model, and interaction terms between GFR and other risk factors were not statistically significant.

Conclusions: Endothelial function of ITA grafts to release NO is impaired at the time of surgery in patients with chronic kidney disease. (J Thorac Cardiovasc Surg 2017;153:317-24)

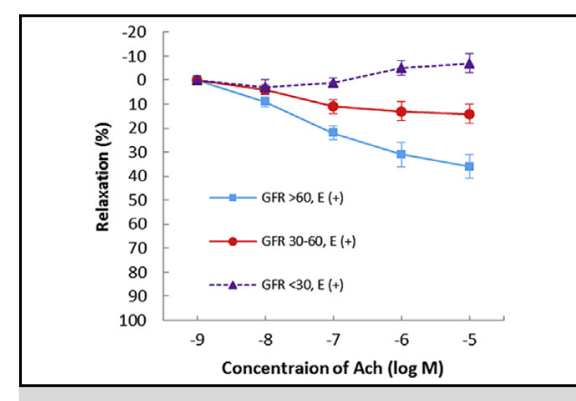

Endothelial function of internal thoracic artery grafts to release nitric oxide was impaired in patients with chronic kidney disease.

\section{Central Message}

Endothelial function of internal thoracic artery grafts to release nitric oxide is impaired at the time of surgery in patients with chronic kidney disease.

\section{Perspective}

Chronic kidney disease is a marker for the severity of endothelial dysfunction in internal thoracic artery graft to release nitric oxide, indicating the association between chronic kidney disease and earlier graft failure and poorer prognosis. Further studies are warranted to clarify mechanisms of this phenomenon and to determine strategies to improve the endothelial function in chronic kidney disease.

See Editorial Commentary page 325
Chronic kidney disease (CKD) has been reported to be associated with a poor prognosis after coronary artery bypass grafting $(\mathrm{CABG}) .^{1-5}$ Although early graft failure is

\footnotetext{
From the ${ }^{\mathrm{a}}$ Division of Cardiovascular Surgery, Department of Surgery, and Departments of ${ }^{\mathrm{b}}$ Pharmacology and ${ }^{\mathrm{c}}$ Anatomy, Shiga University of Medical Science, Otsu, Japan.

This work was supported in part by grant-in-aid for scientific research from the Ministry of Education, Culture, Sport, Science and Technology of Japan (15K19918). Received for publication Jan 26, 2016; revisions received July 26, 2016; accepted for publication Sept 8, 2016; available ahead of print Oct 19, 2016.

Address for reprints: Takeshi Kinoshita, $\mathrm{PhD}$, MD, Shiga University of Medical Science, Setatsukinowa, Otsu, 520-2192, Japan (E-mail: kinotake@belle.shiga-med. ac.jp).

$0022-5223 / \$ 36.00$

Copyright (c) 2016 by The American Association for Thoracic Surgery

http://dx.doi.org/10.1016/j.jtcvs.2016.09.037
}

considered as one of the possible causes, no reliable data exist in terms of graft patency in patients with CKD because angiographic examination with the use of a contrast agent is avoided for fear of radiocontrast-induced deterioration in renal function. We reported previously that CKD is associated with intimal hyperplasia of arterial grafts obtained from patients undergoing coronary bypass

Scanning this QR code will take you to supplemental figures and video for this article.

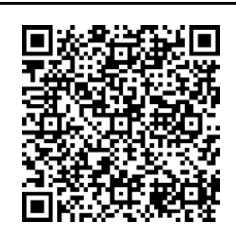




$$
\begin{aligned}
& \text { Abbreviations and Acronyms } \\
& \begin{aligned}
\text { ACh } & =\text { acetylcholine } \\
\text { ADMA } & =\text { asymmetric dimethylarginine } \\
\text { BNP } & =\text { brain natriuretic peptide } \\
\text { CABG } & =\text { coronary artery bypass grafting } \\
\text { CKD } & =\text { chronic kidney disease } \\
\text { EDHF } & =\text { endothelium-derived hyperpolarizing } \\
& \text { factor } \\
\text { GFR } & =\text { glomerular filtration rate } \\
\text { hs CRP } & =\text { high-sensitivity C-reactive protein } \\
\text { ITA } & =\text { internal thoracic artery } \\
\text { LDL } & =\text { low-density lipoprotein } \\
\text { NO } & =\text { nitric oxide } \\
\text { RAS } & =\text { renin-angiotensin system } \\
\text { SNP } & =\text { sodium nitroprusside }
\end{aligned}
\end{aligned}
$$

surgery. ${ }^{6,7}$ This finding indicates that endothelial dysfunction already exists in arterial grafts of patients with CKD at the time of surgery. In the present study, we evaluated the endothelial function of the internal thoracic artery (ITA) graft in patients with CKD.

\section{MATERIALS AND METHODS}

The Human Ethics Committee of Shiga University of Medical Science approved the use of human blood vessels along with the experimental protocol in the present study (Approval no. 25-169). Written informed consent was obtained from each patient.

\section{Vessel Preparation}

Discarded ITA segments were obtained from 110 patients undergoing coronary artery bypass surgery (Video 1). The ITAs were harvested as a skeletonized graft with an ultrasonic scalpel (Harmonic Scalpel; Ethicon Endo-Surgery, Cincinnati, Ohio). The length needed for the revascularization was determined carefully. The redundant distal end was trimmed off and immediately placed in a container with Bretschneider histidine-tryptophan-ketoglutarate solution (Custodiol HTK; Köhler Chemie GmbH, Bensheim, Germany) maintained at $4^{\circ} \mathrm{C}$ and transferred to the laboratory as soon as possible. The adherent connective tissue was dissected carefully, and the arteries were cut helically into 1-cm length strips, with special care being taken to preserve the endothelium. In some strips, the endothelium was removed by gently rubbing the intimal surface with a cotton ball.

Each specimen was fixed vertically between hooks in a muscle bath (10$\mathrm{mL}$ capacity) containing modified Ringer-Locke solution of the following composition: $120 \mathrm{mmol} / \mathrm{L} \mathrm{NaCl}, 5.4 \mathrm{mmol} / \mathrm{L} \mathrm{KCl}, 2.2 \mathrm{mmol} / \mathrm{L} \mathrm{CaCl}_{2}$, $1.0 \mathrm{mmol} / \mathrm{L} \mathrm{MgCl}_{2}, 25.0 \mathrm{mmol} / \mathrm{L} \mathrm{NaHCO}_{3}$, and $5.6 \mathrm{mmol} / \mathrm{L}$ glucose. The bathing media were maintained at a temperature of $37^{\circ} \mathrm{C} \pm 0.3^{\circ} \mathrm{C}$, aerated with a mixture of $95 \% \mathrm{O}_{2}$ and $5 \% \mathrm{CO}_{2}$, and the $\mathrm{pH}$ was 7.36 to 7.43. Before the start of the experiments, the arterial strips were allowed to equilibrate for 60 minutes in the bathing media; during that time, the fluids were replaced every 10 minutes.

\section{Recordings of Mechanical Responses and Experimental Design}

The hook fixing the upper end of the strips was connected to the lever of a force-displacement transducer (TB-611T; Nihon-Kohden Kogyo, Tokyo) connected to an amplifier (AP-621G; Nihon-Kohden Kogyo). Isometric

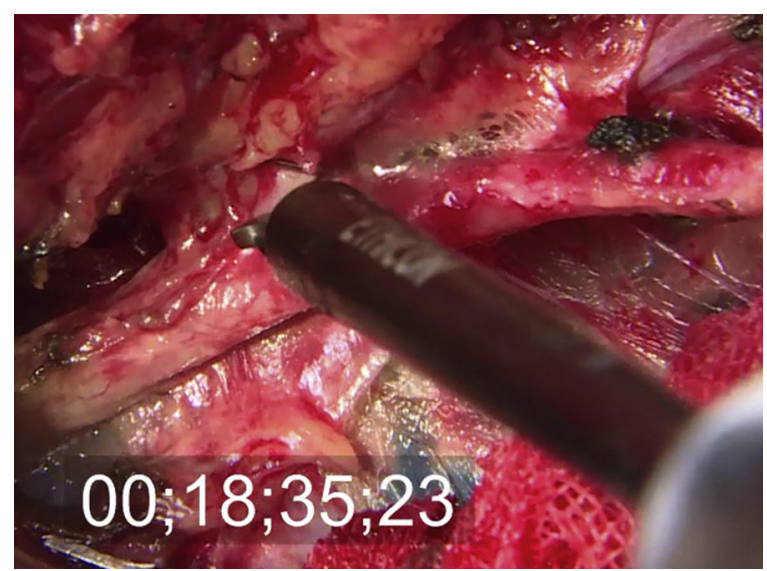

VIDEO 1. Typical example of skeletonized harvesting and off-pump beating coronary artery bypass grafting in our institution. Skeletonization of the left internal thoracic artery (LITA; 00:00-00:32): The LITA was harvested, starting with the endothoracic fascia incised with an electrocautery about 5 to $10 \mathrm{~mm}$ medial to the internal thoracic vein. As the fascia was pulled down with forceps, the undersurface of the vein was exposed with an inactive diathermy tip. The cautery tip was used to gently separate the vein and ITA without activation. An ultrasonic scalpel (Harmonic Scalpel; Ethicon Endo-Surgery, Cincinnati, Ohio) was used to treat small branches of ITA by applying the activated tip gently for a few seconds. Subsequently, protein coagulation was induced, which sealed the cut surface safely. The LITA was harvested near its origin all the way to the subclavian vein, with all branches divided securely in the same way. Anastomoses (00:33-01:08): The skeletonized LITA was used as a pedicled graft to the distal left anterior descending artery. After positioning of the heart, a coronary stent of $2.0 \mathrm{~mm}$ was inserted. Under hemodynamically stable conditions with no arrhythmia, the anastomosis was constructed in an end-to-side fashion with a 7-0 polypropylene running suture. After completion of the anastomosis, the fibrous tissue around the skeletonized LITA was fixed on the heart surface to avoid twisting or kinking. The graft flow was assessed by transit time flowmetry (VeriQc; MediStim, Oslo, Norway) after each anastomosis construction. Video available at: http://www.jtcvsonline.org/ article/S0022-5223(16)31155-2/addons.

contractions and relaxations were displayed on a pen recorder. The resting tension applied to each preparation was adjusted to $1.5 \mathrm{~g}$, which was thought to be optimal on the basis of preliminary experiments. At the start of the experiment, the contractile response to $30 \mathrm{mM} \mathrm{KCl}$ was obtained first. Then, the strips were washed repeatedly with fresh medium and equilibrated. The strips were precontracted partially with phenylephrine (0.1-10 $\mu \mathrm{M})$. After the contraction reached a plateau, concentrationresponse curves for acetylcholine (ACh, $1 \mathrm{nM}$ to $10 \mu \mathrm{M}$ ) and sodium nitroprusside (SNP; a nitric oxide [NO] donor, $0.1 \mathrm{nM}$ to $1 \mu \mathrm{M}$ ) were obtained by adding the drug directly to the bathing media in cumulative concentrations. To prevent synthesis of prostaglandins, the following experiments were performed in the presence of $10 \mu \mathrm{M}$ indomethacin. Some strips were treated with $\mathrm{N}^{\mathrm{G}}$-nitro-L-arginine (an NO synthase inhibitor, $10 \mu \mathrm{M}$ ).

The strips were incubated with blocking agents for at least 30 minutes before we obtained the concentration-response curve for an agonist. At the end of each experiment, $100 \mu \mathrm{M}$ papaverine was added to induce the maximal relaxation, which was taken as $100 \%$ for relaxations induced by the agonists. Integrity of the endothelium was verified histologically by en-face staining of the luminal surface with silver nitrate solution. ${ }^{8}$ Mean values (ranges) of contractile response induced by phenylephrine were $39.8 \%(19.8 \%-57.5 \%)$ of contraction induced by $30 \mathrm{mM} \mathrm{KCl}$, with no significant association with the stage of CKD. 
TABLE 1. Distribution of putative risk factors for endothelial dysfunction by baseline GFR

\begin{tabular}{|c|c|c|c|c|}
\hline & \multicolumn{3}{|c|}{ Baseline GFR, $\mathrm{mL} / \mathrm{min} / 1.73 \mathrm{~m}^{2}$} & \multirow[b]{2}{*}{$P$ value } \\
\hline & $<\mathbf{3 0}$ & $30-60$ & $>60$ & \\
\hline No. patients & 31 & 43 & 36 & \\
\hline Age, y & $71 \pm 10$ & $70 \pm 10$ & $67 \pm 10$ & .01 \\
\hline Female sex & $9(29)$ & $12(28)$ & $10(28)$ & .23 \\
\hline Body mass index, $\mathrm{kg} / \mathrm{m}^{2}$ & $23.3 \pm 3.1$ & $23.6 \pm 3.3$ & $23.4 \pm 3.1$ & .80 \\
\hline Smoker & $14(45)$ & $22(51)$ & $18(50)$ & .26 \\
\hline Hypertension & $24(77)$ & $30(70)$ & $25(69)$ & .12 \\
\hline Systolic BP, mm Hg & $130 \pm 19$ & $123 \pm 17$ & $127 \pm 18$ & .11 \\
\hline Diastolic BP, mm Hg & $61 \pm 13$ & $65 \pm 12$ & $61 \pm 13$ & .34 \\
\hline Diabetes mellitus & $20(65)$ & $25(58)$ & $19(53)$ & .03 \\
\hline Insulin user & $9(29)$ & $10(23)$ & $7(19)$ & .03 \\
\hline Hemoglobin A1c, $\%$ & $6.5 \pm 1.1$ & $6.4 \pm 1.3$ & $6.2 \pm 1.2$ & .09 \\
\hline Peripheral arterial disease & $6(19)$ & $6(14)$ & $3(8)$ & .04 \\
\hline High-sensitivity CRP, mg/dL & $0.30(0.14-1.01)$ & $0.19(0.08-0.52)$ & $0.17(0.07-0.69)$ & .01 \\
\hline LDL cholesterol, $\mathrm{mg} / \mathrm{dL}$ & $89 \pm 31$ & $96 \pm 35$ & $100 \pm 33$ & .07 \\
\hline HDL cholesterol, $\mathrm{mg} / \mathrm{dL}$ & $42 \pm 15$ & $42 \pm 13$ & $45 \pm 12$ & .16 \\
\hline $\mathrm{BNP}, \mathrm{pg} / \mathrm{mL}$ & $216(101-579)$ & $60(24-191)$ & $47(20-128)$ & .01 \\
\hline RAS inhibitor use & $24(77)$ & $35(81)$ & $30(83)$ & .48 \\
\hline Statin use & $27(87)$ & $32(89)$ & $39(91)$ & .77 \\
\hline
\end{tabular}

Data are number (percentage), mean \pm standard deviation, or median (25th-75th percentile). $G F R$, Glomerular filtration rate; $B P$, blood pressure; $C R P, C$-reactive protein; $L D L$, low-density lipoprotein; $H D L$, high-density lipoprotein; $B N P$, brain natriuretic peptide; $R A S$, renin angiotensin system.

\section{Drugs}

The drugs used were ACh (Daiichi-Sankyo Co, Tokyo, Japan); phenylephrine, SNP, $\mathrm{N}^{\mathrm{G}}$-nitro-L-arginine, and indomethacin (Sigma Chemical Co, St. Louis, Mo); and papaverine hydrochloride (Sumitomo Dainippon Pharma Co, Osaka, Japan). Indomethacin was dissolved in sodium bicarbonate buffer ( $\mathrm{pH}$ 9.2). Distilled water was used to dissolve all other drugs and to prepare serial dilutions, as required, from stocks on the day of the experiment.

\section{Definitions}

Glomerular filtration rate (GFR) was estimated from the Modification of Diet in Renal Disease equation: GFR $\left(\mathrm{mL} / \mathrm{min} / 1.73 \mathrm{~m}^{2}\right)=194 \times$ serum creatinine level $[\mathrm{mg} / \mathrm{dL}]^{-1.094} \times$ age $[y e a r]^{-0.287} \times 0.739$ [if female]. $^{9}$ Preoperative serum creatinine was measured at admission. The following risk factors considered to be related to endothelial dysfunction of the ITAs were collected prospectively and entered in our database: age, body mass index $\left(\mathrm{kg} / \mathrm{m}^{2}\right)$, hemoglobin A1c $(\%)$, low-density lipoprotein (LDL) and high-density lipoprotein cholesterol levels (mg/dL), highsensitivity C-reactive protein (hs CRP, $\mathrm{mg} / \mathrm{dL}$ ), and serum brain natriuretic peptide $(\mathrm{BNP}, \mathrm{pg} / \mathrm{mL})$ as continuous variables and sex, smoking $(>10$ cigarettes per day for 1 year), hypertension (defined as blood pressure $\geq 140 / 90 \mathrm{~mm} \mathrm{Hg}$ or as taking an antihypertensive medication), diabetes mellitus (hemoglobin A1c $\geq 6.5 \%$ or currently treated by a physician), peripheral arterial disease (an ankle-brachial blood pressure index $<0.90$ in at least one leg or previous history of surgery), cerebral vascular disease (previous history of ischemic infarction of brain whether symptomatic or silent), and use of renin-angiotensin system (RAS) inhibitors or statins as categorical variables.

\section{Statistics}

Linear relationships between putative risk factors for endothelial dysfunction across the CKD stage, GFR $<30(\mathrm{n}=31), 30$ to 60 $(\mathrm{n}=43),>60 \mathrm{~mL} / \mathrm{min} / 1.73 \mathrm{~m}^{2}(\mathrm{n}=36)$, were analyzed by use of the Mantel-Haenszel linear-by-linear association $\chi^{2}$ test for binary variables and the Jonckheere-Terpstra test for continuous variables. Categorical data are presented as frequencies and percentages. After evaluation of normality by Kolmogorov-Smirnov tests, continuous data are presented as mean \pm standard deviation or as median with 25 th and 75 th percentiles.

To normalize the distributions and improve the linearity, the natural log transform was used for hs CRP and BNP. Comparisons of the maximal ACh- and SNP-induced relaxation between the CKD stage were based on 1-way analysis of covariance, followed by a post-hoc Bonferroni test to detect the individual difference. Precontraction induced by phenylephrine was used as the covariate, and the association between the CKD stage (independent variable) and maximal relaxation response to ACh and SNP (dependent variable) was evaluated. A preliminary analysis showed that the interaction between the covariate and independent variable in the prediction of the dependent variable was not significant, $F(2,104)=0.014$, $P=.986$, indicating that the homogeneity-of-regression assumption was tenable (Figure E1).

To further clarify the association between ACh-induced relaxation and GFR, a multiple linear regression was conducted, with the maximal $\mathrm{ACh}$-induced relaxation as the dependent variable. The potential confounding variables considered were age, female sex, body mass index, smoker versus nonsmoker, hypertension, diabetes, peripheral arterial disease, LDL cholesterol, hs CRP, BNP, and use of RAS inhibitors and statin. In attempt to eliminate multicollinearity, variables that essentially measured the same thing were not entered into the model. Furthermore, multicolinearity between explanatory variables was reduced by centering the variables by subtracting the mean from individual values. We also investigated statistical interactions between $\mathrm{CKD}$ and the following variables, which reached a statistically significance in trend tests: age, diabetes mellitus, peripheral arterial disease, hs CRP, and BNP (Table 1). Multicollinearity of the regression model was examined by calculating variance inflation factor for each variable. None of them exceeded 2 (greatest, 1.28), which indicates that multicollinearity was not a significant issue. All statistical testing was 2 sided. Results were considered statistically significant at a level of $P<.05$. All analyses were performed with the SPSS statistical package, version 20.0 (IBM Corp, Armonk, NY). 


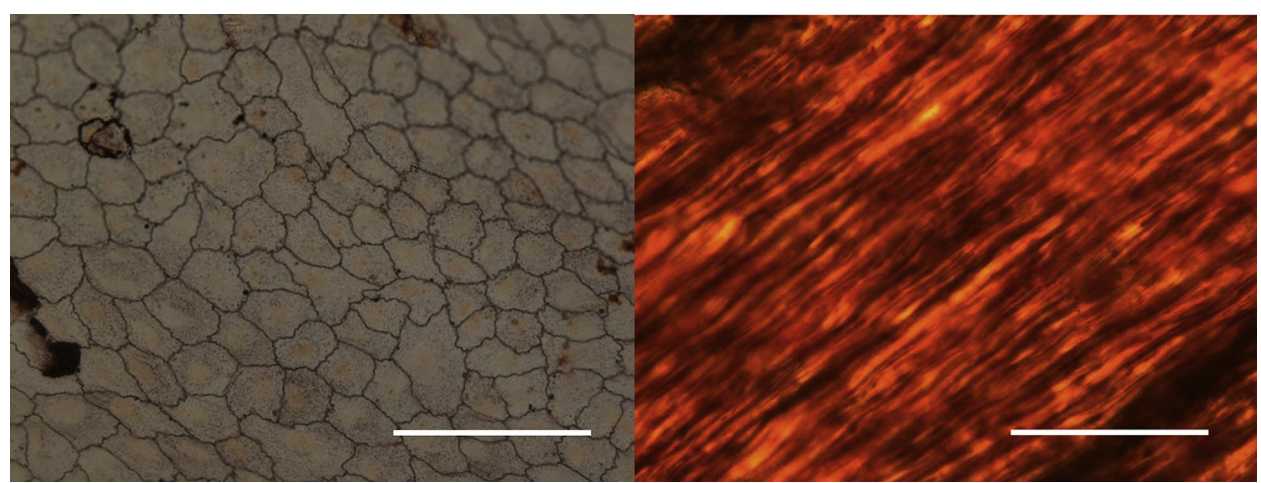

FIGURE 1. Typical example of en-face staining of the luminal surface using silver nitrate solution in endothelium-intact (left panel) and -denuded (right panel) internal thoracic artery strip $(\mathrm{bar}=50 \mu \mathrm{m})$.

\section{RESULTS}

Distribution of Risk Factors for Endothelial

Dysfunction by Baseline GFR Level

The study cohort had a mean GFR of $55.2 \mathrm{~mL} / \mathrm{min} /$ $1.73 \mathrm{~m}^{2}$ (Figure E2). Patients with a lower GFR were significantly older and more likely to have a greater prevalence of poorly controlled insulin-dependent diabetes and peripheral arterial disease and a greater level of hs CRP and BNP (Table 1). No significant difference was found in sex, body mass index, smoker versus nonsmoker,
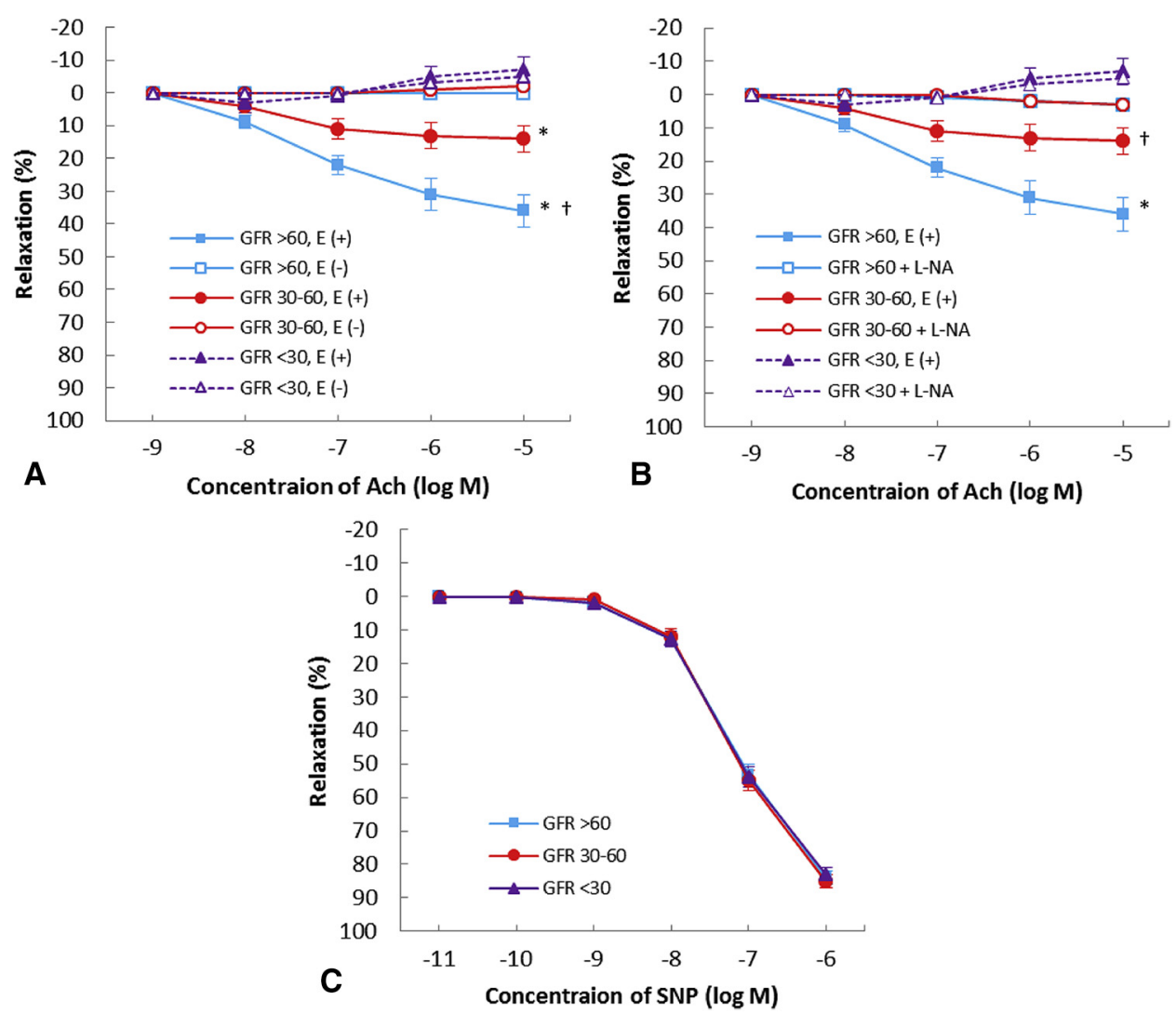

FIGURE 2. Relaxant responses of ITA strips. Data are expressed as means \pm standard error of the mean. Group comparison was performed with the use of an 1-way analysis of covariance and Bonferroni test for post hoc analysis. Precontraction was used as covariate, and the association between the CKD stage (independent variable) and maximal relaxation response to ACh (dependent variable) was evaluated. A, Comparison of ACh-induced relaxations in ITA strips with ( + ) or without ( - ) E among patients stratified by CKD stage (GFR $>60,30-60$, and $<30$ ). $* P<.05$ versus GFR $<30 \mathrm{E}(+), \dagger P<.05$ versus GFR 30-60 E (+). B, Effect of the NO synthase inhibitor on the ACh-induced relaxations in ITA strips with endothelium among patients stratified by CKD stage (GFR $>60,30-60$, and $<30$ ). $* P<.05$ versus GFR $>60+\mathrm{L}-\mathrm{NA}, \dagger P<.05$ versus GFR 30-60+ L-NA. C, Comparison of SNP-induced relaxations in ITA strips with endothelium among patients stratified by CKD stage (GFR $>60,30-60$, and $<30$ ). GFR, Glomerular filtration rate; $E$, endothelium; $L-N A$, $\mathrm{N}^{\mathrm{G}}$-nitro-L-arginine; $A C h$, acetylcholine; $S N P$, sodium nitroprusside. 
TABLE 2. Analysis of covariance for maximal ACh-induced relaxation in endothelium-intact strips by the CKD stage (GFR $<30$, $30-60$, and $>60 \mathrm{~mL} / \mathrm{min} / 1.73 \mathrm{~m}^{2}$ )

\begin{tabular}{lcrrrr}
\hline \multicolumn{1}{c}{ Source } & Sum of square & \multicolumn{1}{c}{ df } & Mean square & \multicolumn{1}{c}{ F } & $\boldsymbol{P}$ value \\
\hline Precontraction & 1193.39 & 1 & 1193.39 & 5.84 & .017 \\
CKD groups & $28,555.56$ & 2 & $14,277.78$ & 69.88 & .001 \\
Error & $21,658.82$ & 106 & 204.33 & & \\
Total & $51,321.09$ & 109 & & & \\
\hline
\end{tabular}

Adjusted $\mathrm{R}^{2}$ of this model was 0.566. CKD, Chronic kidney disease.

prevalence of hypertension, aortic pulse wave velocity, levels of LDL and high-density lipoprotein cholesterol, and use of statins and RAS inhibitors.

\section{Endothelial Integrity of the ITA Strips}

The intimal surface of ITA strips was examined histologically by silver staining immediately after isometric tension study. The histologic endothelial integrity was differentiated clearly in the intact and rubbed strips (Figure 1), which indicates that endothelium of ITA strips remained morphologically intact even after surgical intervention and other experimental protocols.

\section{Vascular Response to ACh and SNP}

In endothelium-intact ITA strips treated with indomethacin and partially contracted with phenylephrine, the addition of ACh produced a concentration-dependent relaxation in patients with GFR $>60$ (Figure 2, A). In patients with GFR 30 to 60 , concentration-relaxation response was observed, but the maximal relaxation was reduced significantly compared with patients with GFR $>60$. In both patient groups, removal of the endothelium or treatment with the NO synthase inhibitor almost abolished the AChinduced relaxation (Figure 2, $A$ and $B$ ). On the other

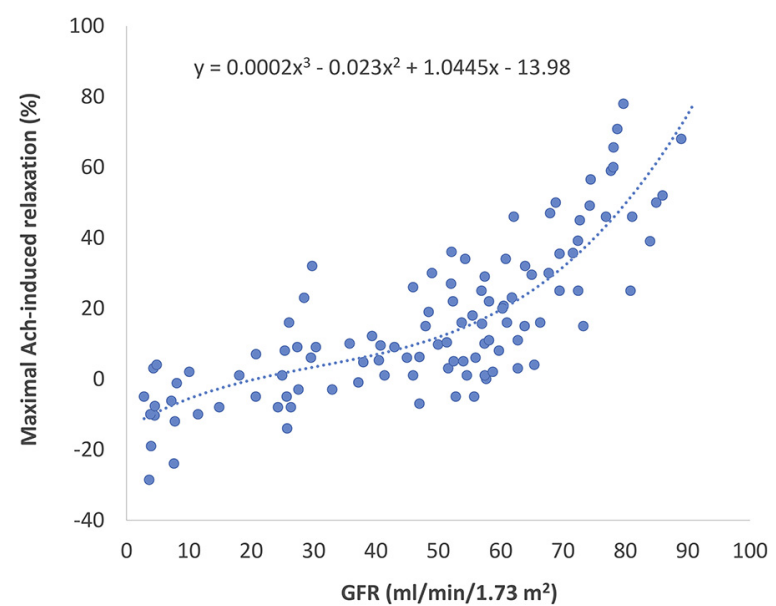

FIGURE 3. Scatter-plots of the relationship between maximal AChinduced relaxation and GFR $(\mathrm{n}=110)$. The best mathematical curve fit was a cubic $\left(\mathrm{R}^{2}=0.686\right)$. GFR, Glomerular filtration rate.
TABLE 3. Multiple linear regression analysis of maximal AChinduced relaxation

\begin{tabular}{lrcc}
\hline & $\boldsymbol{\beta}$ & $\boldsymbol{P}$ value & VIF \\
\hline GFR & 0.55 & .03 & 1.20 \\
Age, y & -0.10 & .51 & 1.28 \\
Female sex & 0.02 & .88 & 1.17 \\
Body mass index & 0.21 & .20 & 1.20 \\
Smoker & -0.22 & .19 & 1.12 \\
Hypertension & 0.05 & .73 & 1.21 \\
Diabetes mellitus & -0.03 & .83 & 1.19 \\
Peripheral arterial disease & -0.17 & .32 & 1.13 \\
High-sensitivity CRP, mg/dL & -0.39 & .09 & 1.18 \\
LDL cholesterol & -0.10 & .49 & 1.25 \\
BNP & 0.20 & .23 & 1.27 \\
RAS inhibitor use & 0.05 & .74 & 1.17 \\
Statin use & 0.02 & .89 & 1.20 \\
GFR*age & 0.19 & .29 & 1.24 \\
GFR*diabetes mellitus & 0.32 & .12 & 1.24 \\
GFR*peripheral arterial & 0.12 & .40 & 1.12 \\
$\quad$ disease & & & \\
GFR*hs CRP & -0.23 & .17 & 1.26 \\
GFR*BNP & -0.30 & .13 & 1.19 \\
\hline D & &
\end{tabular}

Data are expressed as standardized regression coefficients $(\beta)$. Adjusted $\mathrm{R}^{2}$ of the model $=0.634$. VIF, Variance inflation factor; $G F R$, glomerular filtration rate; $C R P$, C-reactive protein; $L D L$, low-density lipoprotein; $B N P$, brain natriuretic peptide; $R A S$, renin angiotensin system.

hand, in patients with GFR $<30$, mild contraction rather than relaxation was induced at a high concentration of ACh (Figure 2, A), which was modified neither by treatment with the NO synthase inhibitor nor by removal of the endothelium (Figure 2, B). Treatment with atropine abolished contraction in endothelium-denuded strips (data not shown). Vasodilator responses to SNP were comparable among the 3 patient groups (Figure 2, C).

One-way analysis of covariance revealed that there was a significant effect of the CKD stage on maximal ACh-induced relaxation after we controlled the effect of precontraction (Table 2). Bonferroni post-hoc tests showed that maximal ACh-induced relaxation (mean \pm standard error of the mean) was statistically significantly greater in patients with GFR $>60(38.0 \% \pm 2.4 \%)$ and those with GFR 30 to $60(10.8 \% \pm 2.2 \%)$ compared with those with GFR $<30(-2.0 \% \pm 2.6 \%)$. There was also a significant difference between patients with GFR $>60$ and those with GFR 30 to $60(P=.001)$. The degree of precontraction also was related significantly to the ACh-induced relaxation. Regarding SNP-induced response, no significant difference was found between the CKD groups (data not shown). The relaxation of endothelium-intact strips to a peak ACh concentration positively correlated with GFR (Figure 3). This relationship held true in a multiple regression model (Table 3). The interactions between GFR and other variables (age, diabetes mellitus, peripheral arterial disease, hs CRP, and BNP) were not statistically significant. 


\section{DISCUSSION}

In the present study, ACh-induced relaxation in endothelium-intact ITA strips under inhibition of cyclooxygenase was reduced significantly in patients with GFR 30 to 60 compared with those with GFR $>60$. In contrast, relaxation response to SNP was preserved regardless of GFR, suggesting that the reduction of ACh-induced relaxation was not caused by a decrease in activation of guanylyl cyclase by NO in vascular smooth muscle cells. The removal of the endothelium or treatment with the NO synthase inhibitor almost abolished the ACh-induced relaxation in patients with GFR $>60$ and 30 to 60, which indicates that $\mathrm{ACh}$-induced relaxation was mediated mainly by endothelium-derived $\mathrm{NO}$ but not by an activation of ACh receptors on vascular smooth muscle cells. Mild contraction observed in patients with GFR $<30$ at a high concentration of ACh was not modified by treatment with the NO synthase inhibitor, suggesting that $\mathrm{NO}$ was not produced by the endothelium in patients with GFR $<30$. Abolishment of contractile response in endothelium-denuded strips by treatment with atropine indicates that this contraction was mediated by activation of $\mathrm{ACh}$ receptors located in vascular smooth muscle cells. These observations indicate that endothelial function of ITA grafts to release NO was impaired at the time of surgery not only in patients with advanced-stage CKD but also in patients with early-stage CKD.

CKD has been shown to be a strong risk factors of long-term mortality and myocardial infarction after CABG and the risk increases in CKD stages. ${ }^{1-5}$ Holzmann and colleagues ${ }^{4}$ examined 6575 patients undergoing CABG and showed that patients with CKD had an increased long-term mortality; hazard ratio 1.8 for patients with GFR 30 to 60 and 5.2 for patients with GFR $<30$, compared with patients with normal renal function. Similarly, we previously reported that patients with CKD had an increased risk of mortality and cardiac-related death independent of other risk factors; 5 -year estimated survival in patients with GFR $<30,30$ to 60 , and $>60$ was $77 \%, 82 \%$, and $93 \%$, respectively $(P=.002)$, and the respective rate free from cardiovascular death was $82 \%, 86 \%$, and $97 \%(P=.001) .{ }^{5}$ It is unclear by which mechanisms CKD affects continual risk of myocardial infarction after complete revascularization. Although bypass grafts theoretically protect myocardium from ischemia as long as they remain patent and functional, CKD may accelerate atherosclerosis of not only native coronary artery but also bypass grafts in those who survive the initial postoperative period. The findings of the present study indicate that CKD is a marker for the severity of endothelial dysfunction in ITA grafts to release NO and support a hypothesis that endothelial dysfunction of ITA results in earlier graft failure and poorer prognosis after CABG in patients with CKD.
Current knowledge of endothelial dysfunction in patients with CKD is based mainly on findings from patients with end-stage renal disease ${ }^{10-13}$ or findings from in vivo assessments in the forearm plethysmography. ${ }^{14}$ Only limited data are available on the endothelial function, which was assessed with the use of an organ bath technique in patients with mild-to-moderate renal dysfunction. van der Harst and colleagues ${ }^{15}$ examined the relationship between renal function and endothelium-dependent and -independent vasodilation response of ITA in patients undergoing CABG by using an organ bath technique and found no relationship between renal function and the vasodilation response. They also showed that contractile response to phenylephrine, potassium chloride, and angiotensin II was not associated with renal function. This result does not concur with ours, but this discrepancy could be explained by the difference in experimental protocols. They did not use inhibitors of cyclooxygenase, so they cannot exclude a possibility that cyclooxygenase-derived vasodilator was involved in the relaxant response to methacholine. Disuse of NO synthase inhibitors in their experiment also leaves open a possibility of a compensatory up-regulation of endothelium-derived hyperpolarizing factor (EDHF) synthesis to maintain a near-normal dilation in patients with CKD. Our experimental protocol including inhibitors of cyclooxygenase and/or NO synthase specifically clarified a reduced release of endothelium-derived NO in patients with CKD.

One mechanism responsible for the decreased response to ACh in patients with CKD is an accumulation of asymmetric dimethylarginine (ADMA), an endogenous and competitive inhibitor of NO synthase. Elevation of plasma concentration of ADMA has been reported in patients with CKD, even in early-stage $\mathrm{CKD},{ }^{16-18}$ and its accumulation is thought to be associated with decreased expression and activity of dimethylargininedimethylamino-hydrolase caused by renal parenchymal damage, rather than with reduced excretion of ADMA from kidney. ${ }^{19}$ Reduction of endothelial NO synthesis caused by ADMA reportedly is associated with increase of oxidative stress, dysregulation of vasomotor tone, ${ }^{20}$ and reduction of the anti-inflammatory and antiplatelet effects of endothelial-derived NO. ${ }^{21,22}$ Clinically, plasma levels of ADMA have been shown to predict adverse cardiovascular events in patients with coronary artery disease $^{23}$ as well as those receiving percutaneous coronary intervention. ${ }^{24}$ The adverse effect of ADMA accumulation on outcome of CABG remains to be determined. To elucidate the association between endothelial dysfunction and ADMA in patients with CKD, we need another study to examine the association between the ability of endothelium to synthesize NO or EDHF, plasma concentration of ADMA, and expression of NO synthase and 
dimethylarginine-dimethylamino-hydrolase in vascular strips of patients undergoing CABG. Other possible explanations include a decrease in NO production and/or an increase in NO degradation before binding to soluble guanylyl cyclase. A decrease in NO production may result from reduced availability of substrates and cofactors for NO synthases, such as tetrahydrobiopterin or L-arginine, from a decreased expression of endothelial NO synthase, or from a decreased activation of endothelial NO synthase, such as phosphorylation of the enzyme or interactions with proteins such as calmodulin or heat shock protein 90 . NO degradation can be enhanced by the binding of NO to hemoglobin or from oxidative stress, which gives rise to peroxynitrite, a vasculotoxic substance.

EDHF has been reported to be synthesized in ITA grafts and accounts for $40 \%$ of net endothelial relaxation. ${ }^{25,26}$ Hence, there is a possibility that EDHF plays a role as a backup system during NO deficiency. In our experiment, NO synthase inhibitor completely abolished ACh-induced relaxation in endothelium-intact ITA strips in the presence of indomethacin, so it is highly possible that AChinduced, endothelium-dependent relaxation was mediated mainly by NO. Compensatory involvement of EDHF, however, cannot be completely denied in our experimental protocol. Endothelium-derived constricting factors also should be taken into consideration, including endothelin-1, cyclooxygenase-derived prostanoids, reactive oxygen species, dinucleotide uridine adenosine tetraphosphate, and angiotensin II.

The study has a number of potential limitations. First, only distal ITA segments were studied, so vascular function at the proximal and midportion of the vessel was unclear. Second, measurements of GFR were based on a single serum creatinine, which could have been influenced by unstable cardiac status and preoperative medications. Third, the lack of follow-up data did not allow us to determine the impact of endothelial dysfunction at the time of surgery on the graft patency or clinical outcomes. Fourth, we targeted at ITA and did not include comparable bypass conduits (saphenous vein, radial artery, and gastroepiploic artery). Further studies are necessary to examine the association between CKD and endothelial function of other conduits to establish an optimal strategy of coronary revascularization in patients with CKD. Fifth, only skeletonized ITAs were enrolled in the present study; however, pedicled ITA grafts might lead to a different result. Perivascular adventitial adipose tissue, which usually is removed by skeletonization, has been reported to release a transferable adventitium-derived relaxing factor that might play a role in compensation for a reduced production of endothelial-derived $\mathrm{NO}$ in patients with $\mathrm{CKD} .^{27,28}$ Another important concern of skeletonization harvest is an injury of arterial wall, especially endothelium. Therefore, we placed importance on histologic validation of endothelial integrity by silver nitrate staining. Sixth, chronic use of oral calcium antagonists or beta blockers might modify the reactivity of ITA grafts; however, we focused on only statin and RAS inhibitor as potential confounders because they have been studied intensively and shown to influence endothelial function. ${ }^{29,30}$

Finally, the study design did not allow us to clarify detailed mechanisms for the blunted relaxant response to ACh in endothelium-intact strip in patients with CKD. In a future study, several possibilities are needed to be investigated to explain the mechanism, including abnormalities in signal transduction, reduced expression of NO synthase, reduced availability of substrate such as L-arginine, reduced availability of cofactor (tetrahydrobiopterin), increased antagonism of NO synthase (ADMA), and accelerated inactivation of NO caused by high levels of oxygen-derived free radicals. Furthermore, we need to examine the beneficial effects of some materials such as L-citrulline ${ }^{31}$ and AVE3085, ${ }^{32}$ which have been shown to protect endothelium from impairment of ADMA on CABG conduits in patients with CKD.

In conclusion, the endothelial function of ITA grafts to release NO is impaired at the time of surgery not only in advanced-stage patients with CKD but also in early-stage patients with CKD undergoing CABG. Further studies are warranted to clarify mechanisms of this phenomenon and to determine strategies to improve the endothelial function in patients with CKD.

We are grateful to Drs Shoichiro Shiraishi and Masato Koike of the Division of Cardiovascular Surgery in Oumikusatsu Tokusyukai Hospital for their important contributions to the experiments.

\section{References}

1. Zakeri R, Freemantle N, Barnett V, Lipkin GW, Bonser RS, Graham TR, et al Relation between mild renal dysfunction and outcomes after coronary artery bypass grafting. Circulation. 2005;112:I270-5.

2. Hillis GS, Croal BL, Buchan KG, El-Shafei H, Gibson G, Jeffrey RR, et al. Renal function and outcome from coronary artery bypass grafting: impact on mortality after a 2.3-year follow-up. Circulation. 2006;113:1056-62.

3. Cooper WA, O'Brien SM, Thourani VH, Guyton RA, Bridges CR, Szczech LA et al. Impact of renal dysfunction on outcomes of coronary artery bypass surgery: results from the Society of Thoracic Surgeons National Adult Cardiac Database. Circulation. 2006;113:1063-70.

4. Holzmann MJ, Hammar N, Ahnve S, Nordqvist T, Pehrsson K, Ivert T. Renal insufficiency and long-term mortality and incidence of myocardial infarction in patients undergoing coronary artery bypass grafting. Eur Heart J. 2007;28: $865-71$

5. Kinoshita T, Asai T, Murakami Y, Suzuki T, Kambara A, Matsubayashi K. Preoperative renal dysfunction and mortality after off-pump coronary artery bypass grafting in Japanese. Circ J. 2010;74:1866-72.

6. Phung DV, Kinoshita T, Asai T, Suzuki T. Histological and morphometric prop erties of skeletonized gastroepiploic artery and risk factors for intimal hyperplasia. Innovations (Phila). 2012;7:191-4.

7. Kinoshita T, Asai T, Suzuki T, Van Phung D. Histomorphology of right versus left internal thoracic artery and risk factors for intimal hyperplasia. Eur J Cardiothorac Surg. 2014;45:726-31.

8. Abrol RP, Hughes VM, Krueger CA, Cook DA. Detection of endothelium in cerebral blood vessels. J Pharmacol Methods. 1984;12:213-9.

9. Matsuo S, Imai E, Horio M, Yasuda Y, Tomita K, Nitta K, et al; Collaborators developing the Japanese equation for estimated GFR. Revised equations for 
estimated GFR from serum creatinine in Japan. Am J Kidney Dis. 2009;53: 982-92.

10. Morris ST, McMurray JJ, Spiers A, Jardine AG. Impaired endothelial function in isolated human uremic resistance arteries. Kidney Int. 2001;60:1077-82.

11. Stroes ES, Joles JA, Chang PC, Koomans HA, Rabelink TJ. Impaired endothelial function in patients with nephrotic range proteinuria. Kidney Int. 1995;48:544-50.

12. Passauer J, Pistrosch F, Büssemaker E, Lässig G, Herbrig K, Gross P. Reduced agonist-induced endothelium-dependent vasodilation in uremia is attributable to an impairment of vascular nitric oxide. J Am Soc Nephrol. 2005; 16:959-65.

13. Luksha L, Stenvinkel P, Hammarqvist F, Carrero JJ, Davidge ST, Kublickiene K. Mechanisms of endothelial dysfunction in resistance arteries from patients with end-stage renal disease. PLoS One. 2012;7:e36056.

14. Perticone F, Maio R, Tripepi G, Zoccali C. Endothelial dysfunction and mild renal insufficiency in essential hypertension. Circulation. 2004;110: $821-5$.

15. van der Harst $\mathrm{P}$, Smilde TD, Buikema H, Voors AA, Navis G, van Veldhuisen DJ, et al. Vascular function and mild renal impairment in stable coronary artery disease. Arterioscler Thromb Vasc Biol. 2006;26:379-84.

16. Vallance P, Leone A, Calver A, Collier J, Moncada S. Accumulation of an endogenous inhibitor of nitric oxide synthesis in chronic renal failure. Lancet. 1992 339:572-5.

17. Kielstein JT, Böger RH, Bode-Böger SM, Frölich JC, Haller H, Ritz E, et al Marked increase of asymmetric dimethylarginine in patients with incipient primary chronic renal disease. J Am Soc Nephrol. 2002;13:170-6.

18. Caglar K, Yilmaz MI, Sonmez A, Cakir E, Kaya A, Acikel C, et al. ADMA, proteinuria, and insulin resistance in non-diabetic stage I chronic kidney disease. Kidney Int. 2006;70:781-7.

19. Schwedhelm E, Böger RH. The role of asymmetric and symmetric dimethylarginines in renal disease. Nat Rev Nephrol. 2011;7:275-8.

20. Cai H, Harrison DG. Endothelial dysfunction in cardiovascular diseases: the role of oxidant stress. Circ Res. 2000;87:840-4.

21. Yao SK, Ober JC, Krishnaswami A, Ferguson JJ, Anderson HV, Golino P, et al. Endogenous nitric oxide protects against platelet aggregation and cyclic flow variations in stenosed and endothelium-injured arteries. Circulation. 1992;86: 1302-9.

22. Cooke JP, Tsao PS. Cytoprotective effects of nitric oxide. Circulation. 1993;88 2451-4.
23. Schnabel R, Blankenberg S, Lubos E, Lackner KJ, Rupprecht HJ, EspinolaKlein C, et al. Asymmetric dimethylarginine and the risk of cardiovascular events and death in patients with coronary artery disease: results from the AtheroGene Study. Circ Res. 2005;97:e53-9.

24. Lu TM, Ding YA, Lin SJ, Lee WS, Tai HC. Plasma levels of asymmetrical dimethylarginine and adverse cardiovascular events after percutaneous coronary inter vention. Eur Heart J. 2003;24:1912-9.

25. Archer SL, Gragasin FS, Wu X, Wang S, McMurtry S, Kim DH, et al. Endothelium-derived hyperpolarizing factor in human internal mammary artery is 11,12 epoxyeicosatrienoic acid and causes relaxation by activating smooth muscle BK(Ca) channels. Circulation. 2003;107:769-76.

26. Liu ZG, Ge ZD, He GW. Difference in endothelium-derived hyperpolarizing factor-mediated hyperpolarization and nitric oxide release between human internal mammary artery and saphenous vein. Circulation. 2000;102 III296-301.

27. Löhn M, Dubrovska G, Lauterbach B, Luft FC, Gollasch M, Sharma AM. Peri adventitial fat releases a vascular relaxing factor. FASEB J. 2002;16:1057-63.

28. Gollasch M. Vasodilator signals from perivascular adipose tissue. Br J Pharmacol. 2012;165:633-42.

29. Schmieder RE. Mechanisms for the clinical benefits of angiotensin II receptor blockers. Am J Hypertens. 2005;18:720-30.

30. Antoniades C, Bakogiannis C, Leeson P, Guzik TJ, Zhang MH, Tousoulis D, et al Rapid, direct effects of statin treatment on arterial redox state and nitric oxide bioavailability in human atherosclerosis via tetrahydrobiopterin-mediated endothelial nitric oxide synthase coupling. Circulation. 2011;124:335-45.

31. Xuan C, Lun LM, Zhao JX, Wang HW, Wang J, Ning CP, et al. L-citrulline for protection of endothelial function from ADMA-induced injury in porcine coronary artery. Sci Rep. 2015;5:10987.

32. Xuan C, Chang FJ, Liu XC, Bai XY, Liao XL, He GW, et al. Endothelial nitric oxide synthase enhancer for protection of endothelial function from asymmetric dimethylarginine-induced injury in human internal thoracic artery. J Thorac Cardiovasc Surg. 2012;144:697-703.

Key Words: chronic kidney disease, coronary artery bypass grafting, endothelial function, internal thoracic artery, nitric oxide, pharmacology 

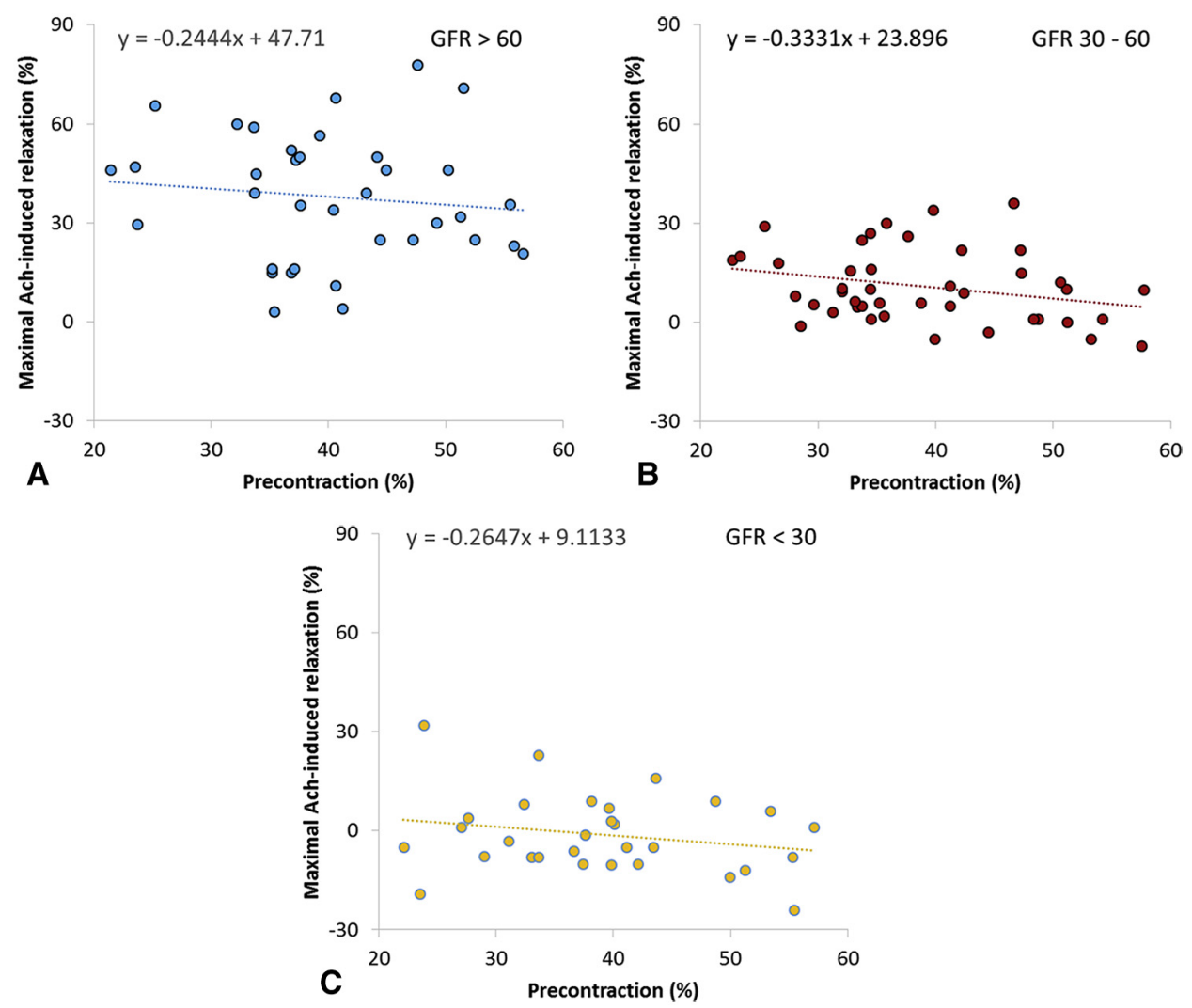

FIGURE E1. Scatter-plot graphs showing the relationship between precontraction and maximal ACh-induced relaxation in patients with GFR $>60$ (A), 30 to 60 (B), and $<30(\mathrm{C}) \mathrm{mL} / \mathrm{min} / 1.73 \mathrm{~m}^{2}$. ACh, Acetylcholine; $G F R$, glomerular filtration rate.

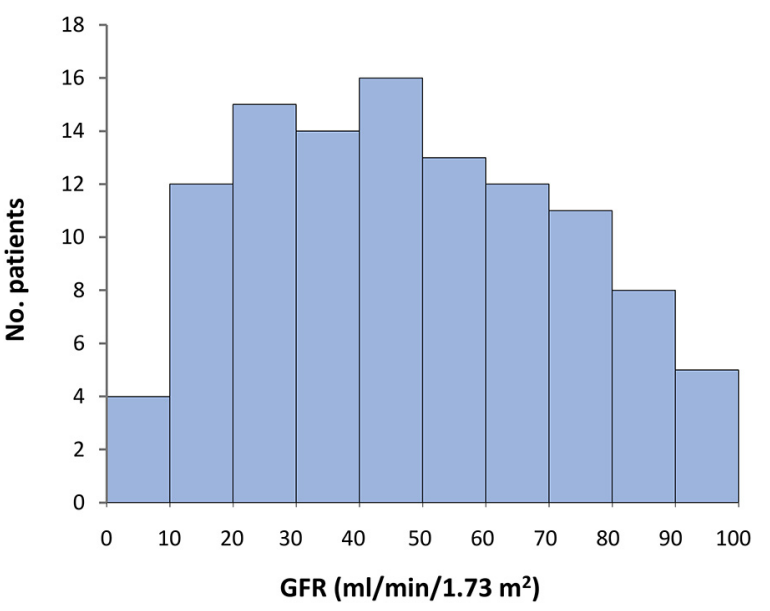

FIGURE E2. Distribution of glomerular filtration rate. GFR, Glomerular filtration rate. 